\title{
A Review on the Country Health System, Its Challenges and the Corrective Solutions
}

\author{
Zahra Ebrahim $^{1} \&$ Amir Ashkan Nasiripour ${ }^{2}$ \\ ${ }^{1}$ MSc Student, Department of Health Services Managment, Electronic Branch, Islamic Azad University, Tehran, \\ Iran \\ ${ }^{2}$ Professor, Department of Health Services Managment, Electronic Branch, Islamic Azad University, Tehran, \\ Iran \\ Correspondence: Zahra Ebrahim Department of Health Services Managment, Electronic Branch, Islamic Azad \\ University, Tehran, Iran. E-mail: Zahra.ebrahim.1366@gmail.com
}

Received: January 12, 2016

doi:10.5539/mas.v10n6p227
Accepted: February 25, 2016

Online Published: June 8, 2016

\begin{abstract}
Health systems have played an important role in improving the lives and increasing life expectancy throughout the twentieth century. However, there are large gaps between potential power of of health systems and its current performance. There are many differences in the achievements of countries with similar resources and facilities and this indicate that many that reforminghealth this system to continue being responsive to the needs of the community is an absolute necessity. Nearly two decades, some efforts have been done to reform the health system and over the years many ups and downshas been seen.

However, reform of health system in Iran is not supported bypolitical sector sufficientely and in term of financial resources relies on financial and technical assistance of "WHO" and a small part of the second loan the World Bank. With regard to the implementation of the reform plan of health system, its role in reaching the goals of the Fifth Development Plan had been implemented since the beginning of 2015. The purpose of this report is to analyze the challenges facing overall health system in Iran and provide proposed solutions in the field.
\end{abstract}

Keywords: health system, reform, challenges and solutions, Iran

\section{The Health and Health System}

One of the most basic needs of human beings is health and all communities need it. Given Twenty-nine constitution, benefit from social security interm of retirement, unemployment, old age, disability, orphanage, homelessness, accidents, injuries and the need for health services and medical care is a universal right and the State shall provideservices and financial support to every individual in the country in accordance to the rules of the general revenue and revenue from the participation of people (Metawie \& Gilman, 2005).

Governments establish organizations to meet the health needs of the community are called the health system. By definition, the health system consists of all organizations and resources that provide health measures and health whether in personal health care, public health services or through intersectoral programs and its main purpose is to improve health.

health system is under intense pressure to improve their performance to deal with issues such as sharp increase in costs, safety issues, quality and justice as well as the aging population, the prevalence of chronic diseases and rising expectations of society, so that in recent years this issue has become a major political concern in most countries. (Bankauskaite \& Dargent, 2007) Improving health system performance requires that they systematically evaluate their performance. (Chang, 2007) Performance can be defined as a set of activities to achieve the preset and macro objectives (Murray \& Frenk, 2000).

Better health is unquestionably the primary goal of a health system. But, health care may lead to catastrophic costs and the need for it is unpredictable, mechanisms of participation and sharing risk and providing financial support are very important, hence, the second purpose of health system ispublic fair participation of people in financing. Meeting people's expectations about issues other than health is third objective that reflects the importance of respecting the dignity, authority and confidentiality of individual's data. 


\section{Atention to the Health System}

One of the most striking features of the contemporary age is dramatic and consistent change in thinking, ideology, social values, work methods, and many other phenomena of life. The speed of these changesis such that the curve can notbe drawn at the time because the development and evolution occurs faster than the speed of drawing the curve. The multitude of changes that organizations are facingcrushedany resistance and takes forward all things.

Need for attention to the health system and performance of the medical community and the need for effective evaluation of activities due to the complexity of this area and as a result, complexity and impact of this important role as protecting the national health system and rapid developments in this field and their interdependence is not secret, performance management provides the ability to modify the route based on changing conditions and to make it dynamic.

Common patterns in the performance assessment of organizations in the world showed need for attention to the performance and the efficiency and effectiveness of the operation and effects of organizational performance especially in the medical community (Mathias et al., 1994).

Transparent and consistent process of evaluating the performance of the medical community in a way which not lead to solve deficiencies orcreate incentives and infrastructure to improve its performance, therefore health system and the medical community require some form of and unique native performance systemwith respect to the diversity: (mission, organization, structure, human resources, etc.)

1. Assess the performance of the medical community,

2. Assess what seeks to measure it. (Validity and reliability)

3. This measure should be precision and acceptable. (Reliability),

4. Based on the needs of the medical community (Macinko, Starfield \& Shi, 2003).

Therefore basic question is: what is the pattern of medical community and health system performance management model that could be a suitable framework for analyzing the strengths and weaknesses provide the medical community with respect to performance, and improve organizational performance?

\section{Challenges and Needs Facing the Health System}

Human health is result ofhistorical interaction of genetic, environmental, psychological, social and ecological each of these factors individually affectshuman health. Apart from different biological and genetic background, physical and ecological environment surrounds human, as well as the economic, political, social and psychological factors effect on man (Lynch et al., 2004).

Human life is changing and these changes in the way people live and work has left a great impact on her health, it tends to change the pattern of disease and death that has been called health transition (Movahedi et al., 2008).

in many countries and to the extent that it affected history, epidemiological changes have been occured including changes in the age pyramid of the aging population, changing pattern of diseases to chronic diseases and accidents associated with the emergence of new technologies and expensive. That makes new demands and as a result of medical progress and its direct impact on health, rising costs in the health sector (Curtis, 2004).

Our country in terms of health risks is under pressure, in fact, because of the passage of health that are part of that comes from underdevelopment and is part of developed societies. Some of these factors are as follows:

Our people are faced poverty, unsanitary methods of waste disposal and waste, indoor smoke from solid fuels, smoking, unsafe sexual relations and nutritional problems caused by lack of energy, vitamins and minerals (vitamins $\mathrm{A}$ and $\mathrm{D}$, iron and zinc) that their bad eating and more eating of overweight, obesity, hypertension and cardiovascular disease.

dangers of high blood pressure and high cholesterol associated with heart attacks and strokes are increasing and the consumption of fatty foods, salty and sweet linked also seem more threatening every day. When these threats are combined with the deadly forces of tobacco and alcohol, are also dangerous. Weight gain and obesity as a result of an increase in food intake and lack of physical activity is itself is considered a major new threat to the health risk. Emerging diseases in turn increases the risk and therefore the costs (Mehrara \& Fazaeli, 2010; Shadpour, 2006).

On the other hand Iran is among the 10 most disaster-prone countries in the world and of the 42 known types of natural disasters in the world, 33 of which occur in our country. Major disasters are floods, earthquakes and droughts. On the other hand, according to Legal Medicine, traffic accidents and road deaths is factor to damage 
about 20 thousand people and injured more than 300 thousand people a year that these events alone causes $16 \%$ of life years lost and pressure increases due to these factors impose a heavy burden on the health system.

Responding to the needs of the community is mission and duty of all organizations that provide services. It is desirable that each organization have such a dynamic and flexible structure with messages that change the environmentand in this way their continuous coordination with the changes provide the environment. Organizations often not the case, especially in traditional societies, this is far from the case.

Among the services that are bound to the needs of society and their organizations are prepared to offer fails and for this reason not recipients of services, and not even the organization of the work carried out and services provided are not satisfied. Because of the nature of health and related services of properties impressionable age advancement of knowledge and technology, time, and various environmental factors that are known to pass health, changing needs of society in this field has accelerated.

Essential health system to have readiness, flexible and efficient enough to deal with these changes, so for achieve these goals, health sector reform to meet the real needs of the health sector as an effective and necessary way. (Reform, 2008)

\section{Evaluation Indices of Healthdistribution}

\subsection{Financial Indicators to Measure Equity}

To measure justice, the following indicatorscan be used: (Bankauskaite \& Dargent, 2007)

\subsubsection{Pay Out of Pocket}

The proportion of health care costs that are paid directly out of pocket when you get the service. Hence further reduce is positive assessment and is mentioned in the Fourth Development Plan. (Reduce out of pocket up to $30 \%)$

\subsubsection{Catastrophic Costs}

The proportion of health costs (including direct and indirect) is calculated to the capacity payment per household. Rise in the index means that households had to spend unreasonable amount of payment capacity to maintain health and treat family members.

According to experts in health economics, the catastrophic cost is happened when total health expenditures paid out of pocket is equal to or more than $40 \%$ of households can afford to pay household or non-food expenses. Further reduce of this index is also positive and is mentioned in the Fourth Development Plan.

\subsubsection{Medical Impoverishment}

The percentage of households shows that in terms of revenue after deducting payments to health fall below the poverty line, ie, experience poverty caused by medical expenses.

\subsubsection{Gini coefficient index}

The Gini coefficient is a measure of statistical dispersion, which is often used to measure inequality in the distribution of income or wealth in a population. This index is defined by a ratio value between zero and one. A low Gini coefficient indicates more equal income or wealth distribution and a higher Gini coefficient determines the unequal distribution. (Baqerilankarani, Lotfi \& Karimian, 2010; Kennedy, Kawachi \& Prothrow-Stith, 1996).

\subsubsection{Fairness inFinancial contribution index}

This index has been described with the aim of measuring amount equity in the distribution of the financial burden of health care costs in 2000 by the World Health Organization as one of the 3 target of health system. Numerator in calculating this index is household expenditures that are directly spent on health and family and the denominator is the cost of non-food household.

Whatever this ratio is equal to the entire household, financing system is fairer and whatever the ratio between different social groups and income households are more, the financing would be unfair. Accordingly justice is the equal right of participation in the payment capacity of households (Xu, 2003; Murray, Frenk, 2001).

4.1.6 Indicator of the health share of gross domestic product (GDP): One of the most important indices of investment in health and health by countries is the share of gross domestic product (GDP) and to the total value of final goods and services produced over a period (one year) within a country. In our country, the figure is about $5 \%$ (according to unofficial statistics, less than 4.6\%) that in this respect we ranked 96th among 190 countries of the world.

Although this figure is slightly higher than the global average in most of our neighboring countries more than 7 
percent in developing countries more than $9 \%$, higher than $12 \%$ in developed countries and in the United States is higher than 16 percent. (Group, 2012) This index reflects the government's attention to the health sector. The low health share of GDP (GDP) on the one hand leads to the reduction in the quality of medical services and on the other hand, in addition to induction of concern, insecurity and the de-motivation of the medical community, leading to direct payments over ordinary people and impose an unfair financial burden (Gerdtham \& Löthgren, 2000).

Inadequate attention to the health share of gross domestic product (GDP) and the allocation of credit to this sectormakes the "per capita" as well as unrealistically low and less than the amount needed to provide treatment and determine the health of the population (Gerdtham \& Löthgren, 2000).

\section{The Functions of the Health System}

\subsection{Stewardship of in Health System}

"Trusteeship" beside the resources, financing and logistics services is one of the four basic functions of the health system and has a direct impact on other functions. According to 2000 World Health Organization defines Trusteeship as a part of the function of a government responsible for the health and well-being of society and the degree of confidence and legitimacy that citizens attach importance to the activities of the government. (Organization, 2000) The major health problems of developing countries trustee WHO views as follows: (Organization, 2000).

- Lack of attention to all the factors and stakeholders in policy-making

- Just pay legislation and regulations and the other components of the stewardship as the production of knowledge and implementation and monitoring of policies and laws fail.

- deliberate lack of attention to some problems like under the table and control the behavior of providers in the private sector

\subsection{Impact of Clinical Governance on Tariff in the Health System}

Given that tariffs is a utility for governance and stewardship and thus leverage for policy, one of the most important challenges facing tariff isthe flawed power stewardship, policy and regulatory changes in the tariff. Important factor in tariffis trustee unit that is virtually absent in our country and there is no unified policy in this area. On the other hand incorrect composition of the High Council of Insurance as the tariff services in the public sector weakened the Ministry of Health as the first power policy in the health sector.

Lack of segregation of duties between the different organs of tariff and non-tariff explanation following the country's tariff policy in the context of another fire damaged power tariff policy in the country. Another problem in this context is that some government agencies and non-governmental are not adhere to the tariffs offered and no significant punitive action in case is done.

So, considering the above mentioned tariff reform in the country more than ever that this is only a result of changes in the structure of policy-making and stewardship of the country it is possible. In this regard, one of the most important steps is to change in power tariff policy authority and custodian of the country including the Ministry of Health has primary responsibility for its implementation and monitoring.

\subsection{Financing (Health Care Financing):}

Methods of health financing in the Islamic Republic of Iran in a way that in most cases, premiums will not increase in proportion to the increase in income persons or families and because of the high proportion of direct payments people the unfair. In the simple employee health insurance premium is no different with senior managers. In new rural insurance scheme, which is run with a focus on family medicine there is no difference between rich and poor and justice is diminished.

This situation way eliminates Job attraction and investment in and lead private sector to small businesses. High insurance premiums due to the informal sector workforce have no desire to join the social security insurance.

In the Islamic Republic of Iran's failure to pay less than the funding system and its complexities are seen. Doctors and staff in public health centers for outpatient treatment services they offer to clients receive salaries. Salary of doctor in public hospitals and specialist centers, in addition to salary, fee for service is complete. Private sector doctors to visit patients (physician office visits) for fee or in the form of "payment for services" be compensated (Mahdavi, 2004).

\subsection{Factors Affecting the Weaknesses of Health Financing in Iran}

There are many factors that lead to weakness and failure in the financing of the health system, but most 
important of these factors include:

1. Contribution of primary health care (PHC) of health spending is about $7 \%$, which is very low compared to international standards.

2. Whatlies in second and third levels of the capture inpatient treatment services is same as the developed countries of the world. (About 57\%), but the high cost, not necessarily in the sense of efficiency in resource consumption.

3. Financial resources devoted to health are very complex and fragmented and is obtained through numerous private and public ways.

4. Unlike Social Security contributionsconstitute a percentage of the employee's salary (30\%) a premium for a fixed sum insured health care organization has received from rich and poor alike.

5. Universal coverage is not complete. According to various data, 10 to 26 percent people dont haveinsurance. Estimated total number of insured is mixed in insurance of various base organizations with overlap and repetition.

6. Major percentage of health funds is provided by direct payments, people (Out of Pocket) in patients for outpatient care, hospitalization, examination and treatment. In addition to these payments, informal payments are done sometimes to escape waiting timeor to achieve a higher quality of provided services.

7. Percentage of direct payments to income people in recent years almost all income deciles is increasing.

8. Only 35 percentage of of households with catastrophic health care costs continue to grow in their insurance coverage.

\subsection{Pooling and Management of Funds}

Health insurance is including social insurance. Basic of social insurance is jobs and income. If public insurance health is implementedproperly mean that any business owner paypremium based on the ratio of income. As a result, more income should pay more and low income pay low. These funds are accumulated in insurance fund.

If there is no insurance coverage, the poor than the rich people; patients compared with healthy individuals and the elderly than younger people are more at risk. Insurance coverage by distributing risks balanced financial burden from the shoulders of the poor, the sick and the elderly (Normand \& Busse, 2002).

In Iran, the funds that are involved in pooling resources and are accumulating risks are numerous including funds to public and semi-public insurance business. Even in the public sector, some have privileges. Cost of insured per capita for the Ministry of Oil, the banking system is several times more than per capita for Social Security or government employee.

Management of some of these funds such as the NHS always is subject to income and expenditure deficit, on the verge of bankruptcy, bad covenant with the contract and the need for financial assistance from the state treasury. Insurance organizations and Imam Khomeini Relief Committee consists of about $90 \%$ of the population in their coverage. While their commitment in finance is about $20 \%$ of the health situation and such health system faced with the difficulties with high sustainability (Shadpour, 2006).

At present, the distribution and the number of funds is nothing but injustice and inefficiency. If the purpose of health insurance is changed the subsidiaries from the rich to healthy and younger people to the poor, the sick and the elderly, the current fund performance do not have such insurance in Iran (Mehrara \& Fazaeli, 2010; Reform, 2008)

Interestingly enough, tariffs for the private sector has been transferred to the medical council and always different tothe tariffs ofpublic sector. In summary, health financing in the countryis not fair. The share of direct payments of people is high are many in the rural insurance program, there is no difference between rich and poor. The share of workers in social security is much higher than international standards.

Insurance funds are very varied, numerous and cut off from each other. Funding to cover the poor strata is not targeted. Distribution of funds in the Ministry of Health also has had not fairness mechanism. Formal and informal payments, overt and covert has wide range and degree of pain hit it first noticed the poor strata. [11]

\section{Human Resources}

\subsection{The Importance of Human Resources in Organizations}

Always, theorists are looking for theoretical relationship between management view of human resource and management practices. Studies show that the relationship between human resource management and 
organizational performance is widespread (Huselid, 1995; West et al., 2002; Arthur, 1994)

National health system is one of the most complicated economic structures of the labor force in each country; this system includes a range of people, including staff offices, to complex medical specialties planning of human resources in the sector with ever increasing difficulties. Human resources function is a component of production resources. From World Health Organization's look at three reasons specific to this function are important [19]

1. Performance of each system depends on combination of skills, manpower availability and performance.

2. A significant portion of the health budget is dedicated to the production and updating of human resources.

3. Due to the weakness management of health human resources in some countries, international financial resources allocated to the difficulties and limitations.

Successful organizations in the world today are organizations that include incorporate organizational. It is no secret that the foundation of any organization is established on the basis of where it needs to meet human need or desire for a permanent change in the new requirements, so the need for change in organizations always be seen on these developments and the need to manage (Mehrolhasani et al., 2013).

The lack of specialization and expertise and clear understanding of the process and barriers to the health system, lack of commitment, lack of experience and level of education, manpower and overall low number of qualified experts and the retirement of some staff lack motivation in staff dissatisfaction with due to the heavy workload and low wages and job security (Lapointe, 2008; Adhikari \& Mellemvik, 2011) leads to the exploitation of the expected benefits of the new system.

Accordingly government should provide training opportunities for managers of information as well as the commitment to education should also be considered in the implementation of this system should be encouraged by all levels of government (Connolly \& Hyndman, 2006; Mahdavi \& Funnel, 2003) On the other hand group meetings for senior managers, middle and operational levels and to inform the staff, to motivate and positive attitude towards this system will help reduce the resistance (Bastani et al., 2012).

The lack of a monitoring and feedback of implementation and the need to draw attention to the importance of the program has caused the operating segments, program execution taken seriously and implemented solely to meet the task involved and any attempt to ease of implementation and its implementation will not solve the problems. This issue has caused the change in the first run form yet and there is already a shortage of skilled manpower in this field (Mahdavi \& Funnel, 2003).

Political environment at the national level to decide on human resources has been sporadically. Provide compensation for the workforce planning, recruitment, promotion, training and human resources management is distributed among different organizations. Coordinating objectives and policies adopted by each of these organizations will be essential to improve human resources in the health sector. In the context of the requirements of the policy must consider two things. It may be a shortage of skilled manpower, inadequate personnel policies for the firms.

As this applies to nurses in health centers is clearly visible and it is feared that in the future the therapy can also occur in other positions. In addition legal gap between doctors and other medical staff and hospital staff and health authorities to protect the health of the country's main burden to bear and wages of low-skilled labor migration.

It is feared unprecedented exodus of medical staff in other European countries and American countries in recent years reached its peak in the not too distant future will severely strain the health system's medical workforce shortage. Hence, the best managers are those who can use the appropriate policies to address these constraints be provided.

\subsection{Corrective Measures}

Ratio of physician more than other health workers has increased in Iran, although the current proportion of GDP than other countries that Iran is similar. However, large numbers of unemployed doctors is a serious matter, particularly for newly graduated doctors to live in cities. This may be the result of low private sector participation in the development of human resources, and most of the resulting distribution of physicians is wrong. Most physicians (84 percent,) live in cities where the competition for jobs, due to the low absorption capacity of the Ministry of Health is very compact.

Only 13 percent of doctors are based in the village. Evaluation of occupied posts with the evaluation of physician manpower shortage, it is necessary to estimate true. Expanding expertise and improve the skills of health personnel, particularly physicians is taking into account demographic changes and epidemiological country was 
alarming trend. Ratio of specialists to general practitioners in Iran has been rising and reached almost 1: 1. [11]

In rural areas and urban pilot programs to strengthen the integration of family physicians in the health care system and establishing full continuity in the care of patients with non-communicable diseases is necessary. This work will help to focus our attention on patient health treatment adhered to coordinate prevention measures, especially at this time that the non-communicable diseases are on the rise. It is important that at least the ideas and options after learning from pilot to practice, appropriate methods to suit the needs of human resources in the country is obvious.

Furthermore, Iran has comprehensive human resources strategy and plan to ensure that the combined number of employees and their skills correspond with the needs of the future is required. Given the above conclusion, the proposed interventions in the category health system functions as follows:

1. Strengthen the expertise body in Educational Affairs Ministry of Health and the communication network with other experts in the field of education and evidence-based policy decisions.

2. Focus on policy, oversight and strategic management and avoidance of enforcement activities in the educational department of the Ministry of Health and Medical Education

3. Consensus on the central part of education programs leading to a degree in the Department of Health

4. Authority for planning, organizing and execution of non-core part of the curriculum at the University of Medical Sciences

5. emphasis on the use of strategies to improve the quality of medical education such as student-centered, problem-based learning, integrated, community-oriented, self-empowerment, flexibility programs and systematic approach to training

6. Explanation and clarification of the cost of training, especially in teaching hospitals

7. Considering the competence and capabilities to create professional knowledge in students (education before graduation) and workers in the medical (in the form of continuing education)

8. Study of improper distribution of forces in urban and rural areas and establish a new strategy for the country. This work should be based on the experience of Iran and at the same time take advantage of international good example.

9. Change the composition and balance of the general practitioner and professional education in medical schools to add to the number of general practitioners and family

10. Policies to attract and retain outstanding teachers

11. Commissioning of the Ministry of Health to monitor the implementation of long-term human resources strategy

Provide a road map and develop a package of development based on the topics identified in this research approach for solving these problems. Create Database in the field, there are specialized teams counseling for employees and create a project management office to coordinate activities, other measures will be proposed in this context.

In general it can be concluded that the proper management of human resources is directly related to productivity and performance of health institutions. These factors can create confidence in the workforce what to do, get timely feedback, feels valued and respected and finally the possibility of increasing the firm's capabilities and growth have. Human resources management and policy fragmentation and lack of human resource managers has two major limitations to the system are fit for human resources management. To overcome this problem, the following policies can be highlighted:

- Appointing Senior Director for Human Resource Management Policies

- Creation of human resource management courses for managers

- Development and skill-based in-service training for workforce

- Strengthen oversight

- Identify inequalities related to workload and Remuneration

\section{Health Information Management}

A dynamic and vibrant health system requires an efficient information system. An efficient information system in the health sector, despite the difficulties and limited resources and unlimited needs can create the most efficient 
and effective. One of the goals of the World Health Organization to support the countries to build health systems that provide effective health care to all people-based approach to primary health care setting. Creating a national health information system that makes it possible to monitor the health care issue is approved by the organization. [31]

A health information system includes the components and methods of organized together in order to produce information that decision-making in the management of health services at all levels of the health system, in health information system data collection, processing, reporting and use of information necessary to improve the effectiveness and efficiency of health services and health care as a result of better management at all levels.

\subsection{Challenges to Health Information Management}

1. Undefined position in the Department of Health Statistics and Information, not given a suitable trustee

2. Shortage of experts and lack of defined tasks and the lack of specialized posts approved for them

3. Lack of commitment from senior ministry officials, senior executives of data and information necessary lack of support, lack of sufficient awareness of the importance of statistics and information to Directors

4. Administrative system is complex and time-consuming

5. Lack of necessary investments to the value of data

6. Lack of laws related to health information management system and the rules relating to intellectual property rights

7. Lack of national health data dictionary

8. Lack of standardization in information cycle, standard data collection standards software

9. Low quality of information

10. Lack of review and improvement of current data, lack of regular reporting and feedback

11. Lack of integration of health information, there are parallel systems of data collection, data dissemination decentralization

12. Lack of motivation among employees in terms of material and spiritual, lack of job security, the lack of proper promoted process

13. Lack of sharing health information system staff in the development of technologies

14. Failure to use the correct and logical hierarchy of computer and statistical software and online data collection

15. Proliferation of technology in environmental levels, lack of attention to the structural capabilities when designing technology

\subsection{Corrective Measures}

Cooperation with the private sector, the health of the private sector, except for a few infectious diseasesis not available to outside view. This means that the bulk of health-related interventions in the country do not count statistics. The participation of private sector representatives in the decision-making is very important for health information standards. Private sector participation in the talks and decisions may be cooperation and a sense of ownership in the sector that adds stability efforts.

It is important that the reporting of the private sector is not laborious or expensive. It is desirable that when the computer information system, information naturally (more or less automatic) where medical intervention or health of flow occurs. Change the current and retrospective data collectionistimely and accountable decision-making. Currently nothing but collect data retrospectively collected data and send it to the higher levels of the health system's hierarchy.

In the past may be the only practical and common, but using today's technologies, enabling new thinking about it. The main disadvantage of the current method of data collection is to accumulate data possible to obtain details of their value during the displacement of the slave and maximize the possibility that in the future it is going to achieve the details to a minimum.

\section{Pharmaceutical Sector}

\subsection{Drug Policy Country}

Our country has the largest consumer proportion drugs in the world. More than 20 billion drug use - in various forms - for a population of 70 million, Iran, namely 300 a year per capita. Each year more than 400 million 
dollars as subsidiary is supplied to support the provision of medication. More than $45 \%$ floating rate is dedicated only 3.5 percent of imported drugs.

Sale rialsof a few drugs with the effect that it is not absolutely justify the high cost of medicines in the country's more than 18 percent of sales. Drug use in the past ten years is over 37 percent. (Shadpour, 2006) In comparison to other middle-income countries, our country has stronger policy achievements, including providing access to medicines and registration of poor sectors and industries capable of creating the national level. Generic drug system applied by the government and international patent medicines (patents) are not recognized.

Drug law related to the period before the Islamic Revolution in Iran is very old and many of the complications resulting from technological advances in medicine and pharmaceutical market conditions; the activities of the national pharmaceutical industry and international cooperation in the field of medicine that actually formed after the Islamic Revolution is not covered.

Iran has a unique medical system in the world. This means that each drug must be registered before the beginning of the process, "the Council's review and formulation of drugs" based Food and Drug Department has been examined and allowed to receive the official list of the country's drug. If the foreign trade and generic drugs already approved by the FDA or European countries and the drug list of the country have been registered are allowed to enter the country.

In this case importers are required to pay $90 \%$ customs duty for import drugs that are able to compete with domestic products. For this reason, for example, foreign kind drugs such as alprazolam is more expensive than about 3 times than Iranian type.

One concern is the issue of drugs trafficking and serious threats in the health system of the country. In some developing countries more than $30 \%$ of the pharmaceutical market of drugs trafficking that is illegally sold in informal markets.

Iran in terms of drug consumption is developing with high consumption of drugs, infection and relatively low consumption of drugs related non-communicable diseases. Data show that the use of antibiotics and drugs is significant that both indicator irrational use of medicines. Currently major medical research is done in universities and research centers and pharmaceutical industry have little contribution in this area. This is while half a percent of revenues Pharmaceutical pharmaceutical industry according to the law should be cost related research.

\subsection{Challenges Facing the Pharmaceutical Industry}

National health policies in the country as part of a more general drug policy must be in harmony with the country. Compilation of "national health policy" orientation will determine the country's pharmaceutical policy and only in this way that the orientation of national drug policies will be capable of planning and evaluation.

\subsection{Some of the Proposed Revisions}

- Encourage the development of the pharmaceutical industry in terms of market

- Remove heavy tariffs (within the stated time table) drugs are imported approaches step by step

- A common fund and investment expertise to develop information technologies.

- Promotion of drug control laboratories to international standards

- addressing counterfeit or sub-standard drugs.

- Strengthen and expand public education on rational use of medicines

- Improve procurement policies and using drugs to hospital

- addressing counterfeit or sub-standard drugs.

- Manage separation of technical regulations

\section{Conclusion}

In this article, a quick look at the challenges in the way of winding the health system in the Islamic Republic of Iran has been conducted. Given the multiplicity of problems and the complexity of the health system in Iran is essential that the authorities are contemplating legislation in the Fifth Development Plan so that the law could bring justice to the people's health. Fourth Development rule is not integrated legal deficiencies and health to a favorable change.

The government and parliament should take a stand on the current health reform. To kind of health system 
reform, commitment authority and the duty and responsibility of the Ministry of Health and Medical Education, the Ministry of Welfare and Social Security, insurance organizations, Management and Planning Organization and other related entities specific to the parallel and shirk the responsibility to minimize the failures of the health sector development plan.

According to well-established culture in the country, according to the preferred treatment of attention to preventive measures in action knows, the main task of the government and the Ministry of Health is to change the overall policy approach by changing the health care system and valuing the individual and social health and changing patterns of nutritional wrong, in all levels of society and at all walks of life especially among disadvantaged and low-income community.

On the other hand, given that the proper management of human resources is directly related to productivity and performance of health institutions, greater attention to this issue could create confidence in the workforce and a sense of worth and respect and the possibility of increasing the capabilities and growth in the health system. Determine experienced senior managers, the creation of human resource management courses for managers, skill-based training for workforce development, strengthen the monitoring and identification of inequalities related to workload and wages and bonuses in this regard can be effective.

Given that the programs that had reduced the country to confront people with catastrophic health expenditures implemented could have a significant impact on the reduction of the index, therefore, we must pay more attention to the issue of the financial participation of various sectors of society and relevant indicators and lack of fairness in financial contribution continue to be felt. It is essential that specific measures to support households living in rural areas in order to protect them from exposure to catastrophic health expenditures and poverty are designed.

One of the most important assessment tools and action plans in the health system of health statistics is performance feedback data from the health community. Hence, special attention should be careful to record data and biological data and information management for the country. Expanding studies in the field of improving the quality of locally manufactured drugs, drug makers create a competitive environment at home and abroad by taking protectionist measures can be effective in improving the country's pharmaceutical system.

\section{References}

Metawie, M., \& Gilman, M. (2005). Problems with the implementation of performance measurement systems in the public sector where performance is linked to pay: A literature review drawn from the UK. In 3rd Conference on Performance Measurements and ManagementControl. 2005. Citeseer.

Bankauskaite, V. and G. (2007). Dargent, Health systems performance indicators: Methodological issues. Presupuestoy Gasto Publico, 49, 125-137.

Chang, L. C. (2007). The NHS performance assessment framework as a balanced scorecardapproach: Limitations and implications. International Journal of Public Sector Management, 20(2), 101-117.

Murray, C. J., \& Frenk, J. (2000). A framework for assessing the performance of health systems. Bulletin of the World Health Organization, 6(78),717-731.

Mathias, M. S. D., et al. (1994). Necessary but not sufficient. Journal of General Internal Medicine, 9(11), 606-615.

Macinko, J., Starfield, B. \& Shi, L. (2003). The contribution of primary care systems to health outcomes within Organization for Economic Cooperation and Development (OECD) countries, 1970-1998. Health services research, 38(3), 831-865.

Lynch, J., et al. (2004). Is income inequality a determinant of population health? Part 2. US national and regional trends in Income inequality and age - and cause - specific mortality. Milbank Quarterly, 82(2), 355-400.

Movahedi, M., et al. (2008). Trend and geographical inequality pattern of main health indicators in rural population of Iran. Hakim Research Journal, 10(4), 1-10.

Curtis, S. (2004). Health and inequality: Geographical perspectives, Sage.

Mehrara, M., \& Fazaeli, A. A. F. A. A. (2010). Health Finance Equity in Iran: an Analysis of Household Survey Data (1382-1386). Journal of Health Administration, 13(40), 51-62.

Shadpour, K. (2006). Health sector reform in Islamic Republic of Iran. Hakim Research Journal, 9(3), 1- 18.

Reform, C. O. P. A. H. (2008). Iranian Health Service Challenges and Solution, M.O.H.A.M. Education, (Ed.), Iran. 
Baqerilankarani, K., Lotfi, F., \& Karimian, Z. (2010). Introduction to Equity in health system2010, Shiraz University of Medical Sciences and Education Development Center: Health Policy Research Center.

Kennedy, B. P., Kawachi, I., Prothrow-Stith, D. (1996). Income distributionand mortality: cross sectional ecological study of the Robin Hood index in the United States. BMJ, 312(7037), 1004-1007.

$\mathrm{Xu}, \mathrm{K}$., et al. (2003). The impact of vertical and horizontal inequality on the fairness in financial contribution index. Healthsystems performance assessment: debates, methods and empiricism. Geneva: World Health Organization.

Murray, C., \& Frenk, J. (2001). World Health Report 2000: a step towards evidence-based health policy. The Lancet, 357(9269), 1698-1700.

Group, W. B. (2012). World development indicators 2012: World Bank Publications.

Gerdtham, U. G., \& Löthgren, M. (2000). On stationarity and cointegration of international health expenditure and GDP. Journal of Health Economics, 19(4), 461-475.

Organization, W. H. (2000). The world health report 2000: Health systems: improving performance2000: World Health Organization.

Mahdavi, M. R. V. (September 2004). Provider payment mechanisms in Islamic Republic of Iran. Wisemen seminar on: Health Politics. Economics, Tehran.

Normand, C., \& Busse, R. (2002). Social health insurance financing. Funding health care: Options for Europe, 59.

Huselid, M. A. (1995). The impact of human resource management practices on turnover, productivity and corporate financial performance. Academic of Management Journal, 38(3): p. 635-72.

West, M. A., et al. (2002). The link between the management of employees and patient mortality in acute hospitals. The International Journal of Human Resource Management, 13(8), 1299-1310.

Arthur, J. B. (1994). Effects of human resource systems on manufacturing performance and turnover. Academy of Management Journal, 37, 670-687.

Mehrolhasani, M. H., et al. (2013). Systematic Review of Examining the Implementation of Accrual Accounting in Public Sector and Health System: Challenges and Solutions. Health Inf Manage, 10(5), 750-760.

Lapointe, S. K. (2008). Accrual accounting implementation in the Canadian Federal Government. Diss, Editor Carleton university: Ottawa.

Adhikari, P., \& Mellemvik, F. (2011). The rise and fall of accruals: a case of Nepalese central government. Journal of Accounting in Emerging Economies, 1(2), 123 - 143.

Connolly, C., \& Hyndman, N. (2006). The actual implementation of accruals accounting: Caveats froma case within the UK public sector. Accounting, Auditing \&Accountability Journal, 9(2), 272 - 290.

Mahdavi, G., \& Funnel, W. (2003). Public sector accountability and accounting information systems in the Islamic Republic of Iran. Iranian Journal of Information Science and Technology, 1(2), 32-45.

Bastani, P., et al. (2012). Iranian Health New Financial Management Reform: Strengths, Weakness and Implications for Future. HealthMED, 6(12), 4035-42.

Petersen, P. E. (2003). The World Oral Health Report 2003: continuous improvement of oral health in the 21st century-the approach of the WHO Global Oral Health Programme. Community Dentistry and Oral Epidemiology, 31(s1), 3-24.

\section{Copyrights}

Copyright for this article is retained by the author(s), with first publication rights granted to the journal.

This is an open-access article distributed under the terms and conditions of the Creative Commons Attribution license (http://creativecommons.org/licenses/by/3.0/). 